\title{
As interações docentes na partilha de saberes 'tardifianos'
}

\author{
Cristianni Antunes Leal ${ }^{1}$ \\ Rosane Moreira Silva de Meirelles 2
}

\begin{abstract}
RESUMO
O saber docente é modelado enquanto profissional pelo acúmulo de experiências, e nas interações docentes há aprendizagens para os profissionais do ensino, assim, a socialização entre professores é considerada um importante recurso para a permanência docente na profissão. Sob tais afirmações o estudo discute os Saberes Experienciais de três professores da área das Ciências Naturais, e os dados coletados foram analisados à luz de Tardif (2014). Os resultados mostraram que há trocas de experiências entre os agentes educativos que se caracterizam como uma formação in loco embora não creditada como em cursos de pósgraduação. Como proposição tem-se a possibilidade de se realizar mini jornadas científicas nas escolas sem ônus para o docente a fim de realizar discussões coletivas que podem contribuir no e para o desenvolvimento profissional, além de propagar a residência pedagógica entre os professores considerados novatos.
\end{abstract}

PALAVRAS-CHAVE: Formação Docentes. Saberes. Ciências Naturais. Educação básica.

Teaching interactions in the sharing of 'tardifian' knowledge

\begin{abstract}
Teaching knowledge is shaped as professional knowledge by experience accumulation, and teacher interactions allow for professional teacher
\end{abstract}

\footnotetext{
${ }^{1}$ Doutora em Ensino em Biociências e Saúde. SEEDUC-RJ, Rio de Janeiro, Brasil. https://orcid.org/0000-00016178-0221.caleal1@gmail.com.

${ }^{2}$ Doutora em Biologia Celular e Molecular. Programa Stricto sensu em Ensino em Biociências e Saúde - Fiocruz/ Universidade do Estado do Rio de Janeiro - DECB/IBRAG/UERJ, Rio de Janeiro, Brasil. https://orcid.org/00000002-9560-2578.rosanemeirelles@gmail.com.
} 
learning. Thus, teacher socialization is considered an important resource for teacher maintenance in the teaching profession. Under these assertions, this study discusses the Experiential Knowledge of three teachers in the Natural Sciences area. The collected data were analyzed under a Tardif (2014) view. The results demonstrate that experience exchanges among educational agents can be characterized as an in loco formation, although not credited as such in postgraduate courses. A proposal is made concerning the possibility of holding mini-scientific events in schools without burdening teachers, in order to carry out collective discussions that can contribute to and for professional development, as well as propagate pedagogical residence among teachers considered novices.

KEYWORDS: Teacher training. Knowledge. Natural Sciences. Basic education.

$$
* * *
$$

O trabalho não é primeiro um objeto que se olha, mas uma atividade que se faz, e é realizando-a que os saberes são mobilizados e são construídos.

Maurice Tardif. (TARDIF, 2014, p. 257).

\section{Introdução}

Maurice Tardif é um pesquisador da área da formação docente e dos saberes. Sua obra aborda as questões dos saberes profissionais dos professores, da formação inicial e continuada dos docentes para a formação do profissional (TARDIF, 2014). Desta forma seu objeto de estudo é a docência e suas relações.

Tardif (2014) define quatro categorias do saber docente: os 'Saberes da Formação Profissional', que ocorrem no decorrer da formação do professor; os 'Saberes Disciplinares', que se organizam em saberes definidos e selecionados pela instituição universitária; os 'Saberes Curriculares' que são os conhecimentos que os professores se apropriam ao longo da carreira como as propostas pedagógicas; e os 'Saberes Experienciais' (ou de 
experiência) que são os saberes práticos quando os docentes estão em seu trabalho cotidiano (na sala de aula).

No Saber Experiencial, objeto de análise deste artigo, considera-se que os professores acumulam vivências que os fazem tomar decisões mais rápido, que causam impacto no ensino e que os ajudam a conviver no ambiente escolar e com seu objeto de trabalho: os estudantes. Assim, é considerado importante a partilha de conhecimento entre os congêneres, ou seja, a socialização docente. Todavia, a coletividade na escola e sua frequente troca de experiências entre os agentes educativos colaboram para que os docentes aprendam novas tecnologias de ensino que podem ajudá-lo com o seu trabalho junto aos estudantes.

A socialização profissional docente está presente nas escolas e é um importante mecanismo para melhorar a formação em serviço, coopera com o docente, quando este necessita de ajuda e o grupo de docentes o auxilia, mas não é creditada como uma formação continuada em serviço. Além disso, é considerada uma opção do docente em querer aprender com o coletivo, mesmo sendo muito difícil não ser influenciado pelo ambiente escolar.

Junto com os Saberes, o tempo de docência também é considerado importante porque são os anos de experiência na profissão que consolidam um profissional mais seguro para atuação em sala de aula. Tardif (2014) divide em duas fases esse tempo: uma fase de exploração (de 1 a 3 anos) e a fase de estabilização e de consolidação (de 3 a 7 anos) "em que o professor investe em longo prazo na sua profissão e os outros membros da instituição reconhecem as suas capacidades. Além disso essa fase se caracteriza por uma confiança maior do professor em si mesmo" (TARDIF, 2014, p. 85) o que o possibilita apresentar um interesse maior pela aprendizagem de seus estudantes, pois estão menos inseguros na profissão docente.

Os investimentos na sua profissão são as formações continuadas, as trocas de experiências, conversas, visitação a espaços de educação formal, não formal e informal, saídas técnicas, como museus e teatros, palestras, entre outras. Toda essa gama de conhecimento do docente passa a fazer 
parte da cultura do mesmo e este pode usar em algum momento em sala de aula para enriquecer o ensino, resolver uma situação e favorecer a aprendizagem.

Mesmo assim, as experiências vivenciadas na formação inicial podem cooperar para um melhor profissional, como apontam as pesquisas de Zeichner (2010) com o hibridismo por meio do "Terceiro espaço" na educação para a formação docente, pois já deixariam os olhares dos professores da educação básica mais sensíveis ao seu redor.

A falta de diálogo por parte das universidades com as escolas e a inserção dos licenciandos no ambiente escolar, às vezes de forma gradual, outras de forma incisiva, foram e são alvos de críticas deste autor que não vê em nenhuma dessas alternativas uma eficaz formação do futuro docente (ZEICHNER, 2010). É uma parte frágil e criticada pela área que estuda a formação de professores.

Com essa frágil formação iniciou-se nas universidades estadunidenses a pesquisa sobre o "Terceiro espaço" na educação para a formação de professores, um local híbrido, mas que pode suavizar e permitir a interlocução entre as universidades e as escolas da educação básica (ZEICHNER, 2010). O Brasil tem aderido paulatinamente a este "Terceiro espaço", por meio de programas como residência pedagógica, ensino da prática, o Programa Institucional de Bolsas de Iniciação à Docência (PIBID), entre outras iniciativas particulares de cada instituição.

Tardif e Lessard (2014) discutem a docência no aspecto sociológico e concebe os professores como trabalhadores que vendem sua força de trabalho, porém com uma especificidade singular: são os agentes que trabalham com seres humanos, sobre seres humanos e para seres humanos com a intenção de trabalhar cognitivamente junto com os estudantes, sendo assim, a docência é uma profissão de relações humanas e os professores são os mediadores entre o estudante e o conhecimento instituído para o ensino por meio dos currículos escolares. 
Gauthier e colaboradores (2013) apontam que para um professor ensinar não basta apenas ter a formação; portanto, o Saber Experiencial ocupa um lugar importante, porém não sozinho. Assim como as profissões se modificam ao longo da história da sociedade conforme as demandas surgem, com isso, a profissão professor também sofre pressões para melhorar seus resultados - a aprendizagem dos estudantes.

Os problemas educacionais não podem ser isolados do contexto social, político e econômico no qual estão inseridos, pois os seres refletem estes problemas na escola, na sala de aula, nos estudantes (como indivíduos e como coletividade, a turma) e para o professor conseguir conviver com estas questões prontamente, o Saber Experiencial é requerido, como no relato:

Os saberes experienciais têm origem, portanto, na prática cotidiana dos professores em confronto com as condições da profissão. Isso significa que eles residem totalmente nas certezas subjetivas acumuladas individualmente ao longo da carreira de cada docente? Não, pois essas certezas também são partilhadas e partilháveis, nas relações com os pares. É através das relações com os pares e, portanto, através do confronto entre os saberes produzidos pela experiência coletiva dos professores, que os saberes experienciais adquirem uma certa objetividade [...]. O relacionamento dos jovens professores com os professores experientes, os colegas com os quais trabalhamos diariamente ou no contexto de projetos pedagógicos de duração mais longa, o treinamento e a formação de estagiários e de professores iniciantes, todas essas são situações que permitem objetivar os saberes da experiência (TARDIF, 2014, p. 52 - grifo nosso).

Os saberes que cada professor produz em sua atuação docente geram experiências e estas circulam em três relações: tempo (como profissional docente atuante), trabalho (na sala de aula de forma privada com a turma) e a aprendizagem dos saberes profissionais (no exercício do labor com as 
experiências vividas e trocadas). A experiência enquanto docente e a socialização são fontes para o saber ensinar que o profissional adquire cotidianamente e acumula ao longo da carreira (TARDIF, 2014).

No estudo de Arruda et al. (2015) os autores alertam para a importância de ter alguém mais experiente para o ensinamento no trabalho que oriente a construir a socialidade do indivíduo, ou seja, socializar-se com os demais colegas de profissão e até mesmo com os estudantes, a fim de ensinar-lhes os 'macetes' como menciona Tardif (2014).

Os professores apresentam uma série de componentes da tarefa docente e o ensino é a principal função formal de cada professor, mas há uma carga informal de trabalho, tais como: as atividades paraescolares (trabalhos de campo, saídas técnicas, projetos, conselhos escolares), enquadramento disciplinar, vigilância, papel de conselheiro pedagógico, supervisão de estagiários no magistério, entre outras. A desenvoltura do professor convive com cada um deles, além de ser pessoal e intrasferível, mas está constantemente em desenvolvimento de acordo com a característica do docente em se relacionar com a docência de forma mais afetiva (TARDIF; LESSARD, 2014). O docente é um ser aberto e influenciável, ainda mais quando o mesmo percebe que uma experiência observada na escola é relevante para ele e seu exercício como trabalhador.

A socialidade é uma característica que nem todos os seres humanos possuem com desenvoltura, embora sejamos animais sociais. Na docência a socialização é colocada à prova, pois há professores que são efusivos e há os que são introspectivos, há os tímidos, há os que são mais seletivos em sua socialização, entre outros. Seja como for, o trabalho docente fomenta tal característica uma vez que relaciona diretamente com seres humanos, ao menos com os estudantes.

Para que a socialização entre os professores aconteça e assim ocorram as trocas de experiências, alguém com um papel de líder (direção, equipe pedagógica) ou os mais experientes precisam organizar-se para promovê-la. 
Principalmente na recepção de novos professores. Atualmente com as redes sociais as discussões coletivas nem precisam ocorrer presencialmente.

"O ensino é um trabalho interativo" (TARDIF; LESSARD, 2014, p. 231) e os professores interagem com os estudantes de forma reclusa em suas salas de aula e interagem com os demais indivíduos da comunidade escolar de forma mais ampla e vigiada, como a direção. O grupo com qual interagem é dinâmico e diversificado, por isso a todo o momento os professores precisam tomar decisões, os mais experientes tomam mais rápido e com menos erros. Enquanto que todas as interações na sala de aula dependem do docente iniciar algo, denota hierarquia, pois os estudantes não tem autonomia para iniciar a atividade pedagógica (TARDIF; LESSARD, 2014).

A personalidade do professor torna-se uma parte importante para ocorrer, ou não a interação, aprendizado e acumulo de Saberes Experienciais e socialização docente, "é com a experiência adquirida na prática que ele [professor] desenvolve a capacidade de improvisação. Os "profissionais experientes' são rápidos" (TARDIF; LESSARD, 2014, p. 251) em solucionar problemas porque apresentam uma abundância de respostas rotinizadas pelos anos na docência. Os novatos, ou professores principiantes ainda têm menos vivência em conviver com diversas situações da sala da aula.

Penna (2012); Carvalho (2014) e Tocafundo; Nascimento; Moreno (2017) endossam em seus trabalhos os saberes 'tardifianos' no aprendizado cotidiano dos professores, pois no dia a dia aprendem os traquejos do exercício docente com os colegas, por meio de observações, conversas e com o próprio tempo enquanto profissional. Desta forma, a convivência com os pares no ambiente escolar é considerada uma aprendizagem para o exercício à docência.

Portanto é possível haver modificação do docente considerando todas as possíveis influências nos saberes práticos dos professores que são oriundos da prática profissional docente, neles incluem: o conhecimento dos conteúdos, os fenômenos socioculturais que influenciam a prática docente, o 
trabalho interativo, a didática, entre outros que colaboram para o saber docente experiencial.

Acerca da socialização docente, Tardif (2014) estabelece que o magistério apresenta uma longa formação com conhecimentos teóricos e técnicos que os preparam para o labor diariamente, o professor se modifica com o passar do tempo adquirindo características da profissão. Ele aprende a ser professor com a desenvoltura dos Saberes já supracitados, com o tempo, com a cultura pessoal e com a socialização escolar entre os pares. $\mathrm{O}$ autor Maurice Tardif enfatiza a socialização docente para a modelagem do profissional docente experiente. $\mathrm{O}$ saber do professor é modelado no e pelo seu ofício, conferindo-lhe experiências para lidar com situações cotidianas e rotineiras.

Assim, e diante do texto apresentado, o objetivo deste estudo é discutir os Saberes Experienciais citados por Tardif de três professores da educação básica atuantes como docentes na Secretaria de Estado de Educação do Rio de Janeiro (SEEDUC-RJ) com a finalidade de responder à pergunta: existe, ou não, a troca de saberes entre os docentes?

\section{Percurso metodológico}

A coleta de dados foi realizada no ano de 2018, utilizando como instrumento um conjunto de questões o qual foi respondido por três professores da SEEDUC-RJ, da área das Ciências Naturais e com diferentes períodos de serviço na rede pública de ensino. Os professores participantes do estudo não se conhecem e trabalham em diferentes escolas. Os dados coletados foram os relatos ipsis litteris dos profissionais do ensino que foram analisados a partir da ideia do compartilhamento de saberes entre os professores como premissa para a aprendizagem docente de Tardif (2014) os Saberes Experienciais.

\section{Apresentação e discussão dos resultados}


No quadro 01 são apresentados os participantes da pesquisa que foram identificados com o símbolo alfanumérico D1, D2 e D3, seguido da formação inicial, de tempo na rede, se possuem ou não pós-graduação e disciplinas que lecionaram em 2018 na SEEDUC-RJ, pois por questões plurais há professores que dão aula de outra disciplina além de sua formação inicial.

QUADRO 01. Perfil dos docentes participantes da pesquisa

\begin{tabular}{|l|l|l|l|l|}
\hline $\begin{array}{l}\text { Identificação } \\
\text { do docente }\end{array}$ & $\begin{array}{l}\text { Disciplina } \\
\text { de formação } \\
\text { inicial }\end{array}$ & $\begin{array}{l}\text { Ano de } \\
\text { ingresso na } \\
\text { SEEDUC-RJ }\end{array}$ & $\begin{array}{l}\text { Pós- } \\
\text { graduação }\end{array}$ & $\begin{array}{l}\text { Disciplina(s) que } \\
\text { lecionou na } \\
\text { SEEDUC-RJ em 2018 }\end{array}$ \\
\hline D1 & Biologia & $\begin{array}{l}2005 \\
(13 \text { anos })\end{array}$ & $\begin{array}{l}\text { Stricto } \\
\text { sensu } \\
\text { Mestrado }\end{array}$ & Ciências e Física \\
\hline D2 & Química & $\begin{array}{l}2010 \\
(08 \text { anos })\end{array}$ & $\begin{array}{l}\text { Não } \\
\text { possui }\end{array}$ & Química e Física \\
\hline D3 & Biologia & $\begin{array}{l}2015 \\
(03 \text { anos })\end{array}$ & $\begin{array}{l}\text { Stricto } \\
\text { sensu } \\
\text { Mestrado }\end{array}$ & Biologia \\
\hline
\end{tabular}

Fonte: elaboração própria

Tardif (2014) e Tardif; Lessard (2014) consideram importante o tempo de ofício para o desenvolvimento da prática pedagógica dos docentes; discutem que a experiência de trabalho é fonte do saber ensinar dos professores. Os autores nomeiam os professores com até cinco anos de magistério de 'novatos', e de 'experientes' aqueles com mais de cinco anos. $\mathrm{O}$ tempo é importante, pois modela a identidade do trabalhador que apresenta um reservatório de experiências para o dia a dia docente, como as questões de indisciplina, gestão de matéria e gestão de classe.

Nas palavras de Tardif: "os conhecimentos profissionais são evolutivos e progressivos e necessitam, por conseguinte, de uma formação contínua e continuada" (TARDIF, 2014, p. 249). Colaboram com as ideias de Tardif as autoras Barbosa; Ursi (2019) quando afirmam que a formação continuada é uma necessidade em um momento com tantas informações, saber gerar 
conhecimento, melhorar sua tecnologia de ensino, deixar de ser um transmissor do conhecimento de outros, são necessidades que os docentes hoje em dia têm. As autoras defendem a Educação a Distância (EAD) como uma proposta para a formação continuada e em serviço, mesmo assim, apresentam os pontos desfavoráveis como um alto número de desistência na EAD.

Ao observar o quadro 01 percebe-se que os professores D1 e D2 lecionam outra disciplina além de sua de formação inicial (a Física), pois são considerados professores habilitados. Para Tardif isso requer do professor "recomeçar sempre, ou quase sempre do zero, e, com o tempo, isso se torna fastidioso e difícil de suportar" (2014, p. 91), o que implica em mais tempo e energia investindo na disciplina que não tem formação para cumprir com suas tarefas: ensinar, avaliar a aprendizagem, estudar a disciplina para não ensinar conceitos errados. O docente sente-se cansado, estressado e preocupado.

O fato dos professores habilitados não terem vivenciado tal experiência na formação inicial e sim, tido estas disciplinas na faculdade de formação de professores, deixa-os mais inibidos e limitados. Por exemplo, professores formados em Ciências Biológicas têm em sua formação inicial disciplinas de Física e Química e isto para a SEEDUC-RJ é o suficiente para habilitá-los a lecinar tais disciplinas na educação básica. De acordo com Zeichner (2010) na maioria dos casos, lecionar disciplinas que não são da formação inicial ou que não fizeram estágio na formação, é um desafio estressante para o docente.

Embora a demanda da educação pública estadual seja com o ensino médio, ainda há municípios no Rio de Janeiro que não contemplam totalmente este nível de ensino. Assim, a SEEDUC-RJ precisa amparar e ofertar o ensino fundamental, que está diminuindo sua oferta, mas ainda existe. É o que acontece com o docente D1, o qual leciona Ciências que é uma disciplina de síntese das Ciências Naturais oferecida somente no ensino fundamental. 
O perfil dos participantes desta pesquisa mostra-se convergente por serem todos docentes efetivos da SEEDUC-RJ e divergentes em suas formações, tempos de serviços, escolas em que trabalham, níveis em que lecionam e formações continuadas.

No quadro 02 são apresentados a pergunta relacionada à prática docente e os relatos dos três professores os quais foram analisados à luz do referencial apresentado.

QUADRO 02. Respostas dos docentes

\begin{tabular}{|c|c|c|}
\hline Pergunta & Docentes & Relatos \\
\hline \multirow{3}{*}{$\begin{array}{l}\text { Qual foi a mais recente } \\
\text { troca de experiência } \\
\text { exitosa que 'conheceu' por } \\
\text { meio de um docente da } \\
\text { SEEDUC-RJ? E se } \\
\text { possivel que tenha } \\
\text { incorporado em sua } \\
\text { prática docente (não } \\
\text { necessariamente ligada à } \\
\text { disciplina que ministra). } \\
\text { Relate, por favor: () } \\
\text { Nunca aprendi nada, ou } \\
\text { () Sim aprendi e foi.... }\end{array}$} & D1 & $\begin{array}{l}\text { Sim. } \\
\text { "As oficinas num evento de aniversário } \\
\text { da escola. Alguns professores foram } \\
\text { convidados, como a de português e a de } \\
\text { sociologia. E foi muito rico. Quando os } \\
\text { colegas admiram o outro, fica mais fácil } \\
\text { contagiar". }\end{array}$ \\
\hline & D2 & $\begin{array}{l}\text { Sim. } \\
\text { "Sim, sempre aprendemos com os } \\
\text { colegas trocas de experiências na } \\
\text { prática do ensino". }\end{array}$ \\
\hline & D3 & $\begin{array}{l}\text { Sim. } \\
\text { "Estratégias para o uso do livro } \\
\text { didático; fazer um dicionário biológico". }\end{array}$ \\
\hline
\end{tabular}

Fonte: elaboração própria

Diante dos relatos destacados acima, é possível afirmar que os três docentes reconhecem que há trocas exitosas com seus pares na SEEDUC-RJ, o que demonstra ser a carreira do magistério criativa, investigativa e que pleiteia uma constante apropriação do conhecimento (NEUMANN; STRIEDER, 2018); e que não ocorre apenas quando é organizada pela Secretaria de Educação. Para Tocafundo; Nascimento; Moreno (2017), os Saberes Experienciais "nascem e se desenvolvem na experiência profissional e na prática cotidiana. Por vezes são tácitos e formam a expertise do professor" (2017, p. 3022) que os possibilitam lecionar porque ajudam a 
modelar a identidade do trabalhador dando-lhe segurança profissional e emocional para o exercício de seu ofício.

Quanto à socialização profissional, objeto de estudo deste trabalho, percebe-se que é presente, no grupo investigado, e importante para evitar equívocos, estresses e um trabalho e trabalhador solitário. A socialização docente é interpretada neste contexto quando um docente observa, troca informações, faz uma residência docente ou mesmo dialoga com agentes educativos mais experientes, principalmente com os professores - que estão ao mesmo tempo em um trabalho individual e coletivo, privado e público que exigem a cada momento tomadas de decisões. E assim passa de um saber individual a um saber coletivo (TARDIF, 2014).

A sala de aula é composta por indivíduos, cada um com o seu tempo de aprendizagem, já que quem aprende é o indivíduo e não a turma, por isso, a socialização entre docentes torna-se importante para aprender a administrar tantas questões que ocorrem com os estudantes e com a escola, tais como: o ensino, a gestão de classe, a aprendizagem, as avaliações, entre outras (ZEICHNER, 2010; GAUTHIER et al., 2013; TARDIF, 2014; TARDIF; LESSARD, 2014).

Quando se atenta para a rede de educação em que a pesquisa foi feita e seu contexto atual, é possível afirmar que a socialização docente é operativa para o profissional docente mesmo que não seja vista pela comunidade escolar, pois não dá certificado, não ocorre necessariamente no local de trabalho, têm várias particularidades de acordo com cada grupo de docentes e região e, às vezes o docente nem se dá conta de que está aprendendo com outro professor (ou outro profissional da educação) que não necessariamente é de sua disciplina, e que pode ressignificar o aprendizado para sua área de atuação.

Com essas situações apresentadas, seguem as discussões dos docentes participantes, seus relatos em relação aos Saberes Experienciais e com a socialização docente por meio das respostas apresentadas no quadro 02.

D1 
Este docente apresenta um desenvolvimento temporal (13 anos) que o permite uma independência que rompe as barreiras disciplinares, apresentando assim, uma autonomia de saberes, podendo produzir, compartilhar, aprender e ressignificar novos saberes. É um docente mais confiante, tanto que em seu relato não há menção à área das Ciências Naturais, percebe que no saber coletivo há algo para sua própria formação docente que pode incorporar em seu habitus (TARDIF, 2014).

Em seu depoimento nota-se que está além das barreiras disciplinares e atento para as demandas de seus estudantes e da comunidade escolar como um todo. Vigilante, está mais confortável em sair de sua área das Ciências Naturais e perceber o mundo real e 'fora das caixinhas cartesianas' disciplinares (TADIF; LESSARD, 2014).

\section{D2}

Aqui o docente está na faixa temporal (08 anos) que já o deixaria mais confortável em suas decisões docente, de acordo com seu tempo de atuação como profissional, mas não citou nenhuma experiência exitosa, sendo generalista em seu relato, o que permite interpretações de que aprendeu vivências positivas e também dissabores em seu exercício profissional, o que também é um Saber Experiencial. Para Tardif (2014) e Carvalho (2014), o ofício docente é um trabalho que lida com situações inusitadas, imprevistas, ou seja, é dinâmico. E para dar conta de toda essa dinamicidade que as relações humanas requerem o docente lança mão de seus saberes acumulados ao longo de toda a sua trajetória enquanto ser humano, mais do que apenas como profissional e com os profissionais.

É um depoimento confuso diante de uma pergunta incisiva, talvez sua visão esteja opaca devido à falta de reflexão na questão da socialização docente, ou sua personalidade seja mais introvertida e pouco socializa com os agentes educativos. A personalidade do docente é uma característica mais rígida a mudanças no ambiente de trabalho, forçar uma adaptação significa se maltratar, o que gera estresse no trabalhador. $O$ docente pode não se sentir à vontade em participar de discussões coletivas ou não tenha tempo 
para participar das interações, como reuniões e culminância de projetos com outras disciplinas e profissionais (TARDIF, 2014; TARDIF; LESSARD, 2014).

\section{D3}

É a docente com uma preocupação maior com o conteúdo de Ciências Naturais e é considerada uma professora novata (03 anos). "No processo de ensino-aprendizagem a atuação do professor é decisiva e, para tanto, a adequada formação inicial e continuada é essencial para sua prática pedagógica e para os resultados do processo na aprendizagem de Ciências" (NEUMANN; STRIEDER, 2018, p. 124). Como esta professora apresenta menos de cinco anos de docência é possível perceber que sua preocupação é maior pelo planejamento e com o seu conteúdo a ser lecionado. Tardif (2014) também aborda isso, pois o professor ainda está nos anos iniciais da docência, estando nas fases da exploração, estabilização e de consolidação, onde se olha mais para si mesmo (como sobreviver à sala de aula) e na matéria que leciona (gestão de aula) do que para os estudantes e suas particularidades (se é necessário adaptar sua metodologia de ensino, se os estudantes aprenderam, entre outros), tanto que cita seu conteúdo disciplinar, mesmo sendo Mestre em Ensino. Contudo, isso é uma fase que é superada com o tempo e com a socialização docente, se a docente assim o desejar.

O ensino de ciências tem uma forte característica de memorização e com muitos conceitos, nomenclaturas e esquemas. A docente D3 está preocupada com estratégias didáticas de ensino de sua disciplina o que pode levar o leitor a interpretar como uma visão mais centrada apenas em sua formação, falta-lhe um olhar mais holístico e sistêmico para compreender o ato de ensinar com um ato social e também político, onde é necessário fazer vários viesses para que seu ensino tenha um real impacto no estudante e este passa a vê-lo além dos muros escolares (GAUTHIER et al., 2013; CHAPANI, 2014; TARDIF; LESSARD, 2014; BARBOSA; URSI, 2019). 
Isto posto, a discussão dos três depoimentos gira em torno do Saber Experiencial e da socialização docente que são considerados importantes para o trabalho do professor junto com o tempo de ofício e a acumulação de experiências. Os relatos estão de acordo com o esperado pelo referencial teórico (PENNA, 2012; GAUTHIER et al., 2013; TARDIF, 2014; TARDIF; LESSARD, 2014).

Por meio dos três depoimentos percebe-se que os Saberes Experienciais permeiam a docência e que o tempo enquanto professor também se faz presente e é importante para a identidade do profissional. $\mathrm{O}$ depoente D1 apresenta-se seguro em sua carreira e com um relato que ventila confiança frente aos demais. Para Tardif (2014) isto significa que está confortável em sua posição e humilde para sempre aprender. O D2 ainda está confuso em suas reflexões sobre o que é aprender, e D3 tenta manter-se segura por meio da elaboração de suas práticas de ensino, que também pode motivar os estudantes. Desta forma "os saberes docentes são temporais, plurais e heterogêneos, personalizados e situados, e que carregam consigo as marcas do seu objeto, que é o ser humano" (TARDIF, 2014, p. 269).

Zeichner (2010) vê na docência a adaptação que o professor principiante precisa fazer ao sair da universidade e ir para o campo de ação. A mudança também passa pelo conhecimento interpretado como 'verdade absoluta' da universidade para o que é aplicável ao campo real das escolas, por isso defende que os professores das universidades e da educação básica, os que recebem estagiários, tenham um constante diálogo para melhorar a formação inicial do licenciando.

Tardif (2014) reitera que o professor não é um mero técnico que transmite conhecimento produzido por outros, mas que os ressignificam e que são atores. O professor aprende muito com os Saberes Experienciais e ainda mais quando tem formação de pesquisador em cursos Stricto sensu torna-se um desejo ideal, mas não é o real a todos profissionais das redes públicas de ensino. A formação em cursos Stricto sensu permite a formação 
de professores-pesquisadores de sua própria prática. E dois do dos três professores deste estudo são Mestres em Ensino.

Os três professores não se conhecem e mesmo assim apresentaram respostas convergentes no "sim", diante de divergências no aspecto cultural, sexo, identidade, tempo como docente e contexto nas cidades onde trabalham, pois tem em comum o Currículo Básico ${ }^{3}$ que não contempla todos os aspectos educacionais, que está desatualizado e que os amarram em seu ensino. O currículo acaba por enclausurar os professores retirando-lhes a autonomia. Ainda que possam subvertê-lo.

Nos relatos dos professores é possível perceber que o tempo "é um fator importante na edificação dos saberes que servem de base ao trabalho docente" (TARDIF, 2014, p. 102), é o tempo para modelar a identidade do profissional e os Saberes Experienciais apresentam uma grande importância, principalmente para os mais novos que ainda estão desenvolvendo sua paridade, vê-se isso no relato do D3 que é considerada uma professora principiante. Tardif (2014) defende a ideia de que esse convívio com outros agentes educativos, inclusive estudantes, modifica os docentes, pois os professores são profissionais que sofrem influência e influenciam outros conforme vão avançando e amadurecendo na carreira profissional. Além de levarem consigo tais experiências para outros locais de atuação, como outros colégios, mesmo que ressignificando-os, como segue no relato:

O que se propõe é considerar os professores como sujeitos que possuem, utilizam e produzem saberes específicos ao seu ofício, ao seu trabalho. A grande importância dessa perspectiva resiste no fato de os professores ocuparem, na escola, uma posição fundamental em relação ao conjunto dos agentes escolares: em seu trabalho cotidiano com os alunos, são eles os principais atores e

\footnotetext{
3 Currículo Básico da SEEDUC-RJ, primeiramente denominado 'Currículo Mínimo'. Disponível em: <http://www.rj.gov.br/c/document_library/get_file?uuid=5b6fba01-8dfe-4d56-a93a-47f941 cfeddb\&groupId=91317>. Acesso em: 12 de abr. de 2019.
} 
mediadores da cultura e dos saberes escolares. Em suma, é sobre os ombros deles que repousa, no fim das contas, a missão educativa da escola (TARDIF, 2014, p. 228 - grifo nosso).

É necessário haver tempo para discussões coletivas que colaborem para a promoção dos Saberes Experienciais, estas discussões favorecem o desenvolvimento profissional. "O tempo de aprendizagem do trabalho não se limita à duração da vida profissional, mas inclui também a existência pessoal dos professores, os quais, de certo modo, aprenderam seu ofício antes de inicia-lo" (TARDIF, 2014, p. 79), pois frequentaram o ambiente escolar enquanto educandos por pelo menos 16 anos, além da formação em nível superior.

Com o tempo de magistério e por acumular experiências compreendese que "só os profissionais são capazes de avaliar, em plena consciência, o trabalho de seus pares" (TARDIF, 2014, p. 248) e julgar se vale ou não como uma boa vivência para ser incorporada, replicada, ressignificada e contextualizada, o que demonstra haver um olhar mais atento ao redor do que ocorre no ambiente escolar, fazendo e aprendendo experiências exitosas e compartilhando-as com outros docentes. Entretanto este julgamento e reflexão ocorrem conforme os profissionais do ensino vão se sentindo mais confiantes na profissão e, se apresentam o desejo em melhorar enquanto profissional.

Vale ressaltar que a pergunta feita neste estudo foi a respeito de experiências exitosas, mas nada impede que experiências negativas (vividas e/ou compartilhadas), como: insatisfações, decepções, contratempos, aborrecimentos, casos de violência, entre outros, não sejam classificados como Saberes Experienciais, elas são.

De forma geral, os três docentes afirmaram haver partilha de saberes por meio das interações docentes, mesmo diante da ausência de políticas proativas ou contrapartida da SEEDUC-RJ em investir na formação continuada. Penna (2012) assegura que as aprendizagens se dão ao longo da 
carreira, no exercício da docência e em momentos de socialização profissional. Mesmo assim os órgãos públicos não podem se privar de oferecer uma formação continuada de qualidade e sem ônus para o trabalhador.

Na obra de Tardif; Lessard (2014) os autores têm uma visão muito política do ato do trabalhador docente, por meio da sociologia da educação, ao afirmarem que o professor age conforme seus empregadores esperam, mas nada impede que os mesmos venham a agir de forma mais transgressora e não se limitem apenas as suas disciplinas, ao contrário, forme pessoas para o mundo real e com conhecimentos que vão cooperar para o desenvolvimento do indivíduo hoje estudante, mas também cidadão. Neste quadro, os autores veem a docência como uma proletarização do trabalho docente, mas capaz de mudanças em si e com forte influência nos demais por meio da socialização. Neste contexto a socialização ocorre entre todos da comunidade escolar, inclusive com os estudantes.

"A escola é como uma organização que oferece serviços e onde predomina o elemento humano" (TARDIF; LESSARD, 2014, p. 49), é uma organização social e a classe/turma torna-se a unidade básica do ensino onde quase que totalmente o trabalho docente atua. A função do professor é o trabalho cognitivo junto com os estudantes por meio da ação de ensinar. Para ensinar o professor precisa de diversas características, tais como: sua personalidade, sua relação mais próxima ou não dos estudantes, seu entendimento como trabalhador de relações humanas, sua relação afetiva, o conhecimento do conteúdo a ser lecionado, entre tantas outras.

Apenas a exposição professoral não basta hoje para os estudantes presente nas classes (BARBOSA; URSI, 2019). Embora o docente esteja em uma posição de poder em relação aos estudantes, é necessário posições e práticas pedagógicas que colaborem para a aprendizagem dos educandos porque "não existe uma maneira objetiva ou geral de ensinar, visto que cada professor dá à sua prática as cores das suas próprias relações com outras pessoas" (TARDIF; LESSARD, 2014, p. 271). O ato de ensinar do docente vai 
se modificando com o Saberes Experienciais e com as interações entre os agentes educativos, com o tempo.

Chapani (2014) afirma em seu estudo que a formação em serviço não é valorizada, pois "não se insere numa perspectiva de educação permanente" (2014, p. 51), talvez por isso os Saberes Experienciais não sejam interpretados como formativos por todos os professores, e sim como uma forma de sobreviver à docência. Enquanto que Arruda et al. (2015) dizem que a formação no trabalho, na troca de saberes com o outro profissional colabora para a aprendizagem no trabalho que é a aprendizagem decorrente da prática profissional e isso ocorre ao longo da vida e com ação social e histórica compartilhada coletivamente. São duas opiniões divergentes que demonstram o quão diverso é a área de formação docente, mas as autoras deste trabalho coadunam com as ideias de Arruda et al. (2015). Enquanto que Chapani (2014) traz dados dos próprios professores, o que os próprios interpretam como formação.

Para Penna os professores "aprendem mais com o exercício docente que nos cursos de formação, ou seja, foi com a prática que aprenderam os traquejos do seu trabalho" (2012, p. 43) e na prática há as interações entre os professores. Tal pensamento corresponde com o observado nas fases iniciais da carreira, a socialização docente, entre os profissionais de ensino e a trajetória profissional que sempre concebem em novas experiências. Isto corresponde à ausência de um espaço intermediário entre a formação inicial e a prática profissional que permite a reflexão dos agentes envolvidos na formação inicial (ZEICHNER, 2010).

Para Tardif (2014) os processos de aprendizagem docente são realizados em socialização com outros profissionais do meio escolar, como o resultado encontrado neste pequeno estudo. O que demonstra a importância dos processos de socialização promovidos pela e na escola, como reuniões pedagógicas e realização de projetos em comum, que se caracterizam em uma formação em serviço, mesmo que não oficial, pois não há certificação e nem conta como experiência a ser comprovada no currículo do profissional. 
Por fim, apesar do cenário penoso do estado do Rio de Janeiro (que decretou estado de calamidade pública em 2016) em fevereiro de 2019 a SEEDUC-RJ anunciou o retorno de cursos de formação para docentes, com o projeto de formação continuada por meio do programa de capacitação de professores "Capacita Rede" 4 , para os cursos: "Ferramentas Digitais na Educação' e 'Inclusão Escolar de Alunos com Necessidades Educacionais Especiais'. Cursos ministrados na modalidade à distância e ainda com poucas vagas considerando o número de servidores desta pasta. Contudo, os professores não foram consultados sobre o que queriam aprender. Coaduna com a ideia de Tardif quando afirma: "em suma, seu poder [professor], não somente na vida dos estabelecimentos escolares, mas na organização e no desenvolvimento de seu próprio trabalho, é realmente muito reduzido" (TARDIF, 2014, p. 243). Ou seja, os professores não foram consultados sobre os cursos e não houve opção de escolha para cursos formativos, porém inscreve-se quem desejar, não é uma imposição. Sobre a oferta de cursos pela Secretaria de Educação, já é um (re)início.

\section{Considerações finais para novos inícios}

Reconhece-se ser um perfil muito pequeno para generalizar os achados a todos os docentes da SEEDUC-RJ, contudo, como a escolha dos professores foi aleatória podem ser interpretados como uma pequena representação do que se encontra como resposta entre os professores que afirmam existir troca de saberes entre si. A partilha ocorre também entre exemplos negativos e o professor aprende o que não fazer.

$O$ fato de haver partilha de saberes entre os docentes pesquisados não isenta a SEEDUC-RJ de investir na formação continuada de seu corpo docente e de formar em serviço sem ônus para o trabalhador, e de preferência no ambiente escolar. A socialização profissional permite a aprendizagem e ajuda no desenvolvimento da identidade profissional.

\footnotetext{
${ }^{4}$ Disponível em: < http://www.rj.gov.br/web/seeduc/exibeconteudo?article-id=10919587>. Acesso em: 30 de mar. de 2019.
} 
Contudo, a Secretaria de Educação têm suas responsabilidades que não a dispensa de investir em seus profissionais da educação.

Já o aprender e o ensinar dos professores se modifica com o tempo, com a personalidade do trabalhador e com as mudanças sociais, como exemplo atual é o uso e interação constante com os dispositivos móveis e redes sociais como agentes mediadores das relações sociais que não foram considerados por Tardif (2014), de forma contundente, mas que contribuem para as interações entre os trabalhadores. O distanciamento da Secretaria de Educação permite a mobilização de novas ações em prol dos Saberes Experienciais entre os pares. Os profissionais vão-se alinhando e adequando-se às novas demandas do trabalho e da sociedade com seus semelhantes.

As interações docentes por meio da socialização dos professores e com a partilha de saberes 'tardifianos' ocorre no ambiente escolar, mesmo que não seja visualizada, creditada e considerada importante pela comunidade escolar por faltar reflexão à questão, mas é para aquele docente que está buscando ajuda, que é novato, que sente-se inseguro em fazer novas incursões, que se sente abandonado pela Secretaria de Educação, mas que está rodeado por estudantes que esperam dele uma posição para o ensino. Um ensino que muitas vezes extrapola sua disciplina de atuação, mas que ajuda o professor a se desenvolver em um melhor profissional e com uma melhor interação com os estudantes e seu trabalho.

Portanto, deixa-se como proposição que após reconhecer que há partilha de saberes entre os docentes aqui pesquisados, é possível sugerir mudanças para o ensino que é o reconhecimento de que tais partilhas ocorrem, e possibilitar que isto se faça in loco, com mediadores para gerir as discussões, tempo para o planejamento e com os próprios pares, diga-se professores da educação básica que conhecem a sala de aula, almejando-se assim uma melhor formação continuada dos docentes e de outros atores educativos, como uma mini jornada científica nas escolas que possibilitam os Saberes Experienciais, e o desenvolvimento dos profissionais de ensino, 
mesmo que sem a creditação e a certificação que um curso ofertado pela Secretaria da Educação daria, além de propagar a residência pedagógica entre os professores considerados novatos.

Por último, resgata-se a pergunta deste estudo: 'se existe, ou não, a troca de saberes entre os docentes?'. A resposta é sim, diante deste grupo investigado e com a literatura consultada para este estudo, infere-se que na socialização dos pares, no espaço escolar, existe ensino e aprendizagem entre os profissionais do ensino que ampara o exercício docente e colabora na identidade dos agentes do meio escolar. Os professores também aprendem em serviço para melhor efetuar seu trabalho, e esta afirmativa não se limita apenas à professores de Ciências Naturais, mas coaduna com outros atores e em outros contextos sociais. Assim reafirma-se que as interações docentes são importantes para o desenvolvimento do profissional professor.

\section{Referências}

ARRUDA, S.M.; PASSOS, M.M.; ANDRADE, E.C.; PIRATELO, M.V.M. Aprendizagem científica no trabalho. Caderno Brasileiro de Ensino de Física. v. 32, n. $01, \quad$ abr., 2015, p. 263-277. Disponível em: $<$ https://periodicos.ufsc.br/index.php/fisica/article/view/2175-7941.2015v32n1p263>. Acesso em: 23 de mar. de 2019.

BARBOSA, P.P.; URSI, S. Motivação para formação continuada em Educação a Distância: um estudo exploratório com professores de Biologia. Enseñanza de las ciências. v. 18, $\mathrm{n}^{\circ}$ 01, p. 148-172, 2019. Disponível em: $<$ http://reec.uvigo.es/volumenes/volumen18/REEC_18_1_8_ex1312.pdf>. Acesso em: 23 de mar. de 2019.

CARVALHO, A.V. Os saberes docentes nas visões de Paulo Freire e Maurice Tardif: uma contribuição. Góndola, enseñanza y aprendizaje de las ciências. v. 09, n. 02 , jun/dic., 2014, p. 34-43. Disponível em: <https://revistas.udistrital.edu.co/ojs/index.php/GDLA/article/view/5761/10442>. Acesso em: 23 de mar. de 2019.

CHAPANI, D.T. Políticas de formação de professores: o Brasil no contexto da globalização. Góndola, enseñanza y aprendizaje de las ciências. v. 09, n. 01, ene/jun., 2014, p. 47-53. Disponível em: $<$ https://revistas.udistrital.edu.co/ojs/index.php/GDLA/article/view/7311/9146>. Acesso em: 22 de mar. de 2019. 
GAUTHIER, C.; MARTINEAU, S.; DESBIENS, J-F.; MALO, A.; SIMARD, D. Por uma teoria da pedagogia: pesquisas contemporâneas sobre o saber docente. Tradução: Francisco Pereira de Lima. $3^{\text {a }}$ ed. Ijuí, RS: Unijuí, 2013.

NEUMANN, S.; STRIEDER, D.M. Formação de professores em nível médio: um estudo de caso sobre o ensino de ciências. Góndola, enseñanza y aprendizaje de las ciências. v. 13, n. 01, 2018, p. 120-132. Disponível em: $<$ https://dialnet.unirioja.es/servlet/articulo?codigo $=6750762>$. Acesso em: 22 de mar. de 2019.

PENNA, M.G.O. Aspectos da prática docente: formação do professor e processos de socialização. Educação: Teoria e Prática. v. 22, n. 39, jan/abr., 2012, p. 38-55. Disponível em: $<$ http://www.periodicos.rc.biblioteca.unesp.br/index.php/educacao/article/view/4510/ 4343>. Acesso em: 22 de mar. de 2019.

TARDIF, M. Saberes docentes e formação profissional. Tradução: Francisco Pereira. $17^{\mathrm{a}}$ ed. Petrópolis, RJ: Vozes, 2014.

TARDIF, M.; LESSARD, C. O trabalho docente: elementos para uma teoria da docência como profissão de interações humanas. Tradução: João Batista Kreuch. 9a ed. Petrópolis, RJ: Vozes, 2014.

TOCAFUNDO, R.D.; NASCIMENTO, S.S.; MORENO, A. Reflexões sobre o distanciamento entre saberes teóricos e práticos na formação acadêmica de professores de educação básica. Enseñanza de las ciências. n. Extra, 2017, p. 30213026. $<$ https://www.raco.cat/index.php/Ensenanza/article/view/339799/430764>. Acesso em: 22 de mar. de 2019.

ZEICHNER, K. Repensando as conexões entre a formação na universidade e as experiências de campo na formação de professores em faculdades e universidades. Revista Educação. Tradução: Marcelo de Andrade Pereira. v. 35, n. 03, set/dez., 2010, p. 479-503. Disponível em: $<$ https://periodicos.ufsm.br/reveducacao/article/view/2357/1424>. Acesso em: 06 de abr. de 2019 . 